\title{
Chinese Rural Household Biogas Utilization Analysis Based on the
}

\section{Regional Risk Assessment}

\author{
Zhang Hang \\ School of Economics and Management, Northwest University, 229 Taibai N. Rd. Xi'an, Shaanxi, \\ China710069
}

1535975895@qq.com

Keywords: reginal risk assessment, index construction, rural household biogas, AHP

Abstract: as one of the important means to solve rural energy and environmental problem, construction of rural household biogas is of great significance to promoting rural sustainable development and socialist new countryside construction. In USA, Greece, Sweden and some developing countries, it is extensively researched and widely applied to use straw as biogas fermentation material to produce biomass energy, which plays a positive role in accelerating resource utilization. With constantly improving of straw-to-biogas production technology system and development of new countryside activities, making full use of straw resources will become an inevitable tendency of Chinese biogas development. However, because of the wide geographical distribution of China rural area and great difference between areas, there are differences in the development status of each area. Therefore, based on regional risk assessment, the papers is going to build a regional risk index system of biogas, evaluate risk of rural household biogas in each area of China, carry out empirical analysis of related data in China from 2005 to 2015, and propose policy recommendations, from reginal risk factors of household biogas in the four aspects of raw material supply, system and technology level, temperature guarantee and socio-economic conditions.

\section{Construction of Regional Risk Assessment Index System for China Rural Household Biogas}

\section{Construction of Index System and Weight Assignment on the Basis of AHP}

The index system of this paper is built on four risk criteria level and the level of six secondary indicators of risk, in the principle of significance, dominance, combination of qualitative and quantitative, easy acquisition and operability.

(1) the risk level of raw material supply (B1) mainly refers to risks because of insufficient or unstable supply of fermentation material, and it is the primary indicator of household biogas risk assessment.

(2) the risk level of temperature guarantee B2NowadaysChina household biogas uses the fermentation technology at constant technology, so the higher is the annual average temperature, the better is the biogas and the smaller is the temperature guarantee risk.

(3) the risk level of socio-economic risk (B3). Both indicators, peasant's annual per capital income and illiteracy rate of the population aged over 15, are selected to reflect regional economic support level and acceptance level to the development of household biogas respectively. High per capital income and low illiteracy rate of population are the key to the establishment and sustainable development of the household biogas industry. 
(4) the risk level of system and technology (B4).It is abstractly replaced by biogas production concentration ratio, which means the percentage of nationwide total biogas production taken by reginal biogas production. The higher is the concentration ratio; the better is the development of reginal biogas industry, which indirectly reflects the higher regional system and technology level.

In this paper, the analytic hierarchy process (AHP) is adopted for weight assignment, to divide the complex problems to be identified into several levels, to determine the contribution degree of underlying index to the upper index according to calculation and estimate of feature factor of the matrix, and to finally get the importance degree of the index system and foundational indexes to the total target (Table 1)

Table 1 index system and its weighted value

\begin{tabular}{|c|c|c|}
\hline $\begin{array}{l}\text { Objective } \\
\text { level }\end{array}$ & Criteria level & Index level \\
\hline \multirow{6}{*}{$\begin{array}{c}\text { A) } \\
\text { Risk } \\
\text { assessme } \\
\text { nt index } \\
\text { system of } \\
\text { China } \\
\text { biogas }\end{array}$} & \multirow{2}{*}{$\begin{array}{l}\text { Raw material supply risk } \\
\qquad(\mathrm{B} 1) \\
(0.422)\end{array}$} & $\begin{array}{c}\text { Gross amount of straw resources (B11) } \\
(0.76)\end{array}$ \\
\hline & & $\begin{array}{l}\text { Average growth rate of straw production } \\
\text { for years } \\
(0.24)\end{array}$ \\
\hline & $\begin{array}{c}\text { Temperature guarantee risk } \\
\qquad(\mathrm{B} 2) \\
(0.227) \\
\end{array}$ & $\begin{array}{l}\text { average annual temperature (B21) } \\
(1)\end{array}$ \\
\hline & \multirow[t]{2}{*}{$\begin{array}{l}\text { Socio-economic risk(B3) } \\
(0.226)\end{array}$} & $\begin{array}{c}\text { Annual per capital income of peasant } \\
\text { household (B31) } \\
(0.676)\end{array}$ \\
\hline & & $\begin{array}{c}\text { Illiteracy rate of population aged over } 15 \\
\text { B32 } \\
(0.324)\end{array}$ \\
\hline & $\begin{array}{c}\text { System and technology } \\
\text { risk (B4) } \\
(0.125)\end{array}$ & $\begin{array}{l}\text { Production concentration degree of the } \\
\text { biogas B41 } \\
\text { (1) }\end{array}$ \\
\hline
\end{tabular}

\section{Scoring Standard Setting}

Due to different dimension of each index, the scoring standards are different. Its therefore necessary to make indexes being dimensionless, that is, compare index value with its standard value. In accordance with its risk level, each foundational index can be divided into six scoring classes, namely, 0 point, 20 points, 40 points, 60 points, 80 points and 100 points, which respectively represent no risk, less risk, normal risk, less high risk, high risk and very high risk. Scoring standards of each foundational index in the China biogas straw-resources-based regional risk assessment index system are as follow: 
Table 2 scoring standard of indexes

\begin{tabular}{l|l|l|l|l|l|l|l}
\hline \multirow{2}{*}{$\begin{array}{l}\text { Inde } \\
\mathrm{x}\end{array}$} & \multirow{2}{*}{ Unit } & \multicolumn{6}{|l|}{ Scoring standard } \\
\cline { 3 - 8 } & & 0 & 20 & 40 & 60 & 80 & 100 \\
\hline B11 & $10^{4} \mathrm{t}$ & $(5000$, & $(4000,5$ & 3000,400 & 2000,300 & $(1000,20$ & $(0,1000]$ \\
& & $+\infty)$ & $000]$ & $0]$ & $0]$ & $00]$ & \\
\hline B12 & $\%$ & $(6,+\infty)$ & $(4,6)]$ & $(2,4]$ & $0,2]$ & $(-2,0]$ & $(-\infty,-2]$ \\
\hline B21 & ${ }^{\circ} \mathrm{C}$ & {$[25,+\infty)$} & {$[20,25)$} & {$[15,20)$} & {$[10,15)$} & {$[5,10)$} & {$[0,5)$} \\
\hline B31 & Yua & $(4000,+\infty)$ & $(3500,40$ & $(3000,35$ & $(2500,30$ & $(2000,25$ & $(0,2000]$ \\
& $n$ & & $00]$ & $00]$ & $00]$ & $00]$ & \\
\hline B32 & $\%$ & {$[0,5)$} & {$[5,10)$} & {$[10,15)$} & {$[15,20)$} & {$[20,25)$} & {$[25,+\infty)$} \\
\hline B41 & $\%$ & $(15,+\infty)$ & $(12,15]$ & $(9,12]$ & $(6,9]$ & $(3,6]$ & $(0,3]$ \\
\hline
\end{tabular}

Score of indexes between two adjacent standards can be determined by means of linear interpolation, of which the formula is as follow:

$$
y=\left\{\begin{array}{cc}
y_{i+1}-\frac{x-x_{i+1}}{x_{i}-x_{i+1}}\left(y_{i+1}-y_{i}\right) & \left(x_{i}<x_{i+1}\right) \\
y_{i}+\frac{x-x_{i+1}}{x_{i+1}-x_{i}}\left(y_{i+1}-y_{i}\right) & \left(x_{i}>x_{i+1}\right)
\end{array}(i=0,1,2,3,4,5) \quad \text { Formula } 1\right.
$$

\section{Scoring Model Building}

In this paper, the multi-objective linear weighting function method is used to evaluate reginal risk of China household biogas, which means that the upper index is calculated from the corresponding lower index group. The formula is shown as follows:

$$
\stackrel{\mathbf{u}}{A}=\stackrel{\mathbf{u}}{B} \bullet \stackrel{\mathbf{u}}{W} \quad \text { Formula } 2
$$

In formula 2, A represents upper index; B means vector value of low index; $\mathrm{W}$ refers to weight vector of lower index.

\section{Empirical Analysis of Risk Assessment}

\section{Data Source}

Since the straw species and composition of type structure are of significant difference in the 31 provinces of China and in consideration of characteristic of this paper, agricultural products, like rice, wheat, corn, beans, potatoes, oilseeds, cotton, sugar cane and others, are chosen, of which the production data comes from China statistical yearbook 2005-2015. And data about average annual temperature of each province, annual per capital income of rural peasants and illiteracy rate of the population aged above 15, derives from China statistical yearbook2015. As for average annual 
temperature, average value of three different cities from high to low latitudes in each province is taken. And the data about biogas concentration degree are from 2015 China agricultural statistical data.

\section{Analysis of Evaluation Results at Different Risk Levels}

First, work out specific score of each index according to index scoring standard and formula in Table 2, then figure out evaluation results of each province at different risk level according to index weight and formula in Table 1 and sort ascending. It can be seen that each risk factor is of great regional difference in China.

The risk level of raw material supply (B1). As for material supply, less risky areas are mainly centered on the central and northeast agricultural developed area, while high risky areas are concentrated in northwest agricultural and pastoral areas and economically developed areas in eastern China. This proves that development degree and concentration degree of agricultural production are the key factors determining raw material risk.

The risk level of temperature guarantees (B2). The top five risky provinces are Heilongjiang, Qinghai, Gansu, Sinkiang and Inner Mongolia, followed by Liaoning, Tibet, Ningxia and Jilin, etc. among which, Tibet and Qinghai are located at Tibetan plateau cold area with poor natural conditions; the provinces lower down on the list are Hainan, Guangdong, Guangxi, Fujian, Chongqing and other low-latitude provinces, followed by Hubei, Hunan, Zhejiang, Shanghai, Yunnan and other southern areas.

The risk level of socio-economic risk (B3). Its observed that the top-ranked provinces are Gansu, Guizhou, Tibet, Yunnan, Qinghai and other economically backward provinces in the northwest and southwest of China, as well as Shanghai, Beijing, Zhejiang and other economically developed coastal areas; and the less risky areas are Shandong, Liaoning, Guangdong, Fujian, Hebei and others, where the economy develops fairly well and agricultural production is developed. Generally speaking, acceptance degree of peasant household to the biogas is generally low in areas of higher or lower socio-economic development level, which is not good for the development of regional and rural household biogas industry.

There is a huge difference between system and technology risks, which is calculated from biogas concentration degree. As we can see, the five provinces of Guangxi, Sichuan, Hunan, Yunnan and Henan are less risky, which indicates that regional household biogas develops well in those provinces and their system and technology level is relatively high; however, the risk class of provinces, such as Tibet, Shanghai, Tianjin, Qinghai, etc. is approximately 100, which shows that those areas are limited by their natural condition or socio-economic condition and are not suitable to develop rural household biogas industry.

\section{Analysis of Regional Comprehensive Risk Assessment}

In advantage of different risk assessment results and formulas, it is possible to obtain a straw-resource-based regional comprehensive risk (A) zone division (as displayed in Table 3). As we can see, provinces of lower comprehensive risk are Henan, Shandong, Sichuan, Hebei, Hunan, Guangxi, Hubei, Jilin and Jiangsu, etc. where raw material supply is adequate, temperature is suitable and social-economic development level is general; provinces of higher comprehensive risk, however, are Qinghai, Gansu, Tibet, Ningxia, Sinkiang and other areas of lower agricultural 
development level in northwestern and southwestern China, as well as Beijing, Tianjin, Shanghai, Zhejiang and other economically developed areas in eastern China, and Shanxi, where conventional energy sources are highly concentrated; risk level of the rest is general.

Table3 comprehensive risk zone division of China household biogas areas based on straw resource

\begin{tabular}{l|l|l}
\hline $\begin{array}{l}\text { Name of } \\
\text { risk zone } \\
\text { division }\end{array}$ & $\begin{array}{l}\text { Standard } \\
\text { of risk } \\
\text { zone } \\
\text { division }\end{array}$ & Areas \\
\hline $\begin{array}{l}\text { Low risk } \\
\text { zone }\end{array}$ & $\begin{array}{l}\text { Henan, Shandong, Sichuan, Hebei, Hunan, Guangxi, Hubei, } \\
\text { Jilin and Jiangsu }\end{array}$ \\
\hline $\begin{array}{l}\text { Generalris } \\
\text { k zone }\end{array}$ & $\begin{array}{l}\text { Chongqing, Hainan, Guizhou, Inner Mongolia, Yunnan, } \\
\text { Fujian, Liaoning, Jiangxi, Guangdong, Anhui, Heilongjiang }\end{array}$ \\
\hline $\begin{array}{l}\text { High risk } \\
\text { zone }\end{array}$ & $\begin{array}{l}\text { Qinghai, Beijing, Gansu, Tibet, Shanghai, Ningxia, Zhejiang, } \\
\text { Tianjin, Shannxi, Sinkiang, Shanxi }\end{array}$ \\
\hline
\end{tabular}

\section{Conclusion}

It can be seen from above results that provinces of lower risk level only account for $29 \%$ in China. To improve this situation, the following three recommendations are put forward:

First, in order to avoid further loss and environmental destruction, biogas construction is not suggested for the areas, where the risk level is approximately 100;

Second, to promote biogas construction in provinces of lower risk level and with vast rural areas, the government shall improve the macro control, strengthen policy support to biomass energy development and policy orientation in biomass energy consumption, and decrease market risk of biomass energy consumption, especially in terms of centralized energy purchasing.

Third, take the opportunity of rural household biogas development; create a business-oriented biomass energy innovation system; accelerate the progress of commercialization and industrialization.

\section{References:}

[1] Yu Chen, Gaihe Yang \& Yongzhong Feng. Construction of regional suitability assessment system and research on grading standard for household biogas development [J].agricultural research on arid region, 2008.26(5):228-232

[2] Xiaohua Chen \& Hongguang Zhu. Research progress and prospect of biogas production with crop straw [J]. Agricultural and engineering journal, 2007. 23(3):279-283 
[3] Wenbin Ding, Yapeng Wang \& Yong Xu. Biomass energy material yield potential analysis of major agricultural products [J]. China population resources and environment, 2007.17(5):84-89 